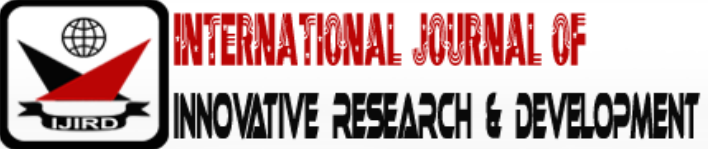

ISSN 2278 - 0211 (Online)

\section{Investigations of Health Impairments Associated with Human Extreme Exposure to RF Radiations}

\author{
Alao Olumuyiwa Ademola \\ Lecturer, Department of Mathematical and Physical Sciences, \\ Afe Babalola University, Nigeria \\ Ajayi Isaac Rotimi \\ Professor, Department of Physics and Electronics, Adekunle Ajasin University, Nigeria \\ Musiliyu Kazeem Adeleke \\ Senior Technologist, Department of Mathematical and Physical Sciences, Afe Babalola \\ University, Nigeria \\ Owolabi Funmilayo Mofoluwaso \\ Assistant Lecturer, Department of Biomedical Technology, \\ Federal University of Technology, Nigeria
}

\begin{abstract}
:
Open waves near the human ear diaphragm with excessive dose are unhealthy for occupational and popular users of cell phones. This necessitate that radio frequency signal be managed based on the procedure of the International Atomic Energy Agency (IAEA) that "the accepted understanding of the term radiation protection is restricted to protection of people". In order to check the spontaneous impulses from the use of mobile phone, our assessments in this study are considered in the tolerance limit for SARs at lower limits of $<1.5 \mathrm{~mW} / \mathrm{kg}$ and the upper limits of $\geq 1.5 \mathrm{~mW} / \mathrm{kg}$. In less than unity agreement with International Commission on Non-Ionizing Radiation (ICNIRP) recommendations, our experimental analysis showed that between $900 \mathrm{MHz}$ and $2200 \mathrm{MHz}$ at conductivities of $0.7665 \Omega^{-1} \mathrm{~m}^{-1}$ and $1.1531 \Omega^{-}$ ${ }^{1} \mathrm{~m}^{-1}$, it is expected that proper absorption of radio frequency pulses that can be converted easily to electrical pulses be maintained.
\end{abstract}

Keywords: Open waves, Long Time Dose (LTD), Radiation dose, Specific Absorption Rate, Power density

\section{Introduction}

The functioning conditions of the cell phones need vital elements in order to keep both occupational and popular users informed with problems of the harms rendered from the concentrate of the radiation dose. The protests of the International Atomic Energy Agency (IAEA) is that the conventional radiation dose is needed to be of the people's understanding and that there is a periodic implication resulting from every exposure. It is however expected that the brain absorbs not more than the irradiations that can be converted easily to electrical pulses by the hormones that responsible for the electrical activity of the brain. The human brain which naturally functions for thinking, emotions and memory is a highly sensitive and complex organ of the nervous system that responds to the electromagnetic radiations that use a wide range of extremely low frequencies (ELF). The open electromagnetic wave from the mobile phone when calls are received interact with the brain tissue and are impulsive to the activities of the brain. Since the brain is a medium that can act as an aerial that absorbs the open waves and convert them to eddy current, then there is substantial uncertainty with energy of maximum dose of non-ionizing radiations or signal photons that the brain can accommodate, there is therefore a need to sustain a safe intake of the microwave radiation that is absorbed.

\section{Review}

Dosimetry analysis is to experimentally determine the specific absorption rate (SAR) distributions in the body. The specific absorption rate (SAR) is the absorbed power per the absorbing mass which is expressed as $\mathrm{Wkg}^{-1}$. The concept involved is used in quantifying the interactions of $\mathrm{RF} /$ microwave radiation with living systems. One way of determining the local or whole-body SAR is by temperature measurement. The Specific Absorption Rate (SAR) is proportional to the temperature increase only when the effects of heat diffusion can be neglected. The frequencies of nonionizing radiations used however in this study ranges mostly between $900 \mathrm{MHz}$ and $1800 \mathrm{MHz}$. The tropical population more importantly Nigeria is associated with the use of Nokia, Samsung, Motorola, Sony, Sony Ericson and I- Tel, Sagem, $\mathrm{Nec}$ and Tecno mobile phones among others and should balance up with suitable indices of Specific Absorption Rate (SAR) as to maintain radiation safety against incident photon from open electromagnetic waves from mobile phones. This study 
or examinations arise due to addictive attitude to cellular usage which amount to Long Time Dose (LTD) of irradiations passing through the earing diaphragms and if cares are not taken would characterize some forms of spontaneous epidemiological reactions in individuals. Nonetheless, the SAR values would be a factor included with features in moderating the maximum possible exposure to RF energy from a particular model of cell phone since SAR value does iterate reactions about the amount of $\mathrm{RF}$ exposure over a certain period of investigations

\section{Experimentation}

The characteristic dielectric parameters considered for this study are the radio frequencies, conductivities and mass densities of varieties of mobile phones. This enables us to compare the experimentally observed differentials of experimented phone devices with radiation dose limits to suite tropical behavioural responses. In various Phone models or species experimentally confirmed with empirical SARs, tolerance characteristic differences were noted. The specific absorption rate (SAR) however gives us the dosimetric measure for our tropical broadband frequencies for GSM Networking. Nonetheless, SAR/ Power density relevance in our low percentage (\%) in the limit of recommendations were taken for $\leq 1.5 \mathrm{~mW} / \mathrm{kg}$ while in the upper limit $>1.5 \mathrm{~mW} / \mathrm{kg}$. These helped in quantify our inferences in terms of parameter of the ICNIRP's (International Commission for Non-Ionising Radiation Protection) safety guide in terms of the parameter as applicable to dosimetry measure. At higher frequencies, many interactions are due to the rate of energy per unit mass.

\begin{tabular}{|c|c|c|}
\hline Frequency (MHz) & $\begin{array}{c}\text { Conductivity, } \boldsymbol{\sigma} \\
\left(\mathbf{\Omega}^{-1} \mathbf{m} \mathbf{m}\right)\end{array}$ & $\begin{array}{c}\text { Mass density, } \boldsymbol{\rho} \\
(\boldsymbol{k g} / \mathbf{m})\end{array}$ \\
\hline 900 & 0.7665 & 1030.0 \\
\hline 1800 & 1.1531 & 1030.0 \\
\hline
\end{tabular}

Table 1: Dielectric Properties for Human Brain Tissue

This Study is concerned with the broadband frequencies associated with tropical Africa, to be considered in the tolerance limit for SARs at lower limits of $<1.5 \mathrm{~mW} / \mathrm{kg}$ and the upper limits of $\geq 1.5 \mathrm{~mW} / \mathrm{kg}$ for the conductivity and mass density as shown in Table 1. It is rarely observed that the $900 \mathrm{MHz}$ compares with same mass density to $2200 \mathrm{MHz}$ but at conductivities of $0.7665 / 1.1531 \Omega^{-1} \mathrm{~m}^{-1}$ for $900 / 1800 \mathrm{MHz}$ range. Table 1 features the relative data for the frequencies used in the tropics- $900 \mathrm{MHz} / 1800 \mathrm{MHz}$, to the advantage of the procedure of the International Atomic Energy Agency (IAEA) against radiation hazards.

\begin{tabular}{|c|c|c|c|}
\hline Frequency (MHz) & $\begin{array}{c}\text { Power density, } \\
\boldsymbol{\sigma}\left(\boldsymbol{\mu} \mathbf{W} / \mathbf{m}^{2}\right)\end{array}$ & $\begin{array}{c}\text { Whole body, SAR } \\
(\boldsymbol{W} / \mathbf{K g})\end{array}$ & $\begin{array}{c}\text { Body Head, SAR } \\
(\boldsymbol{W} / \mathbf{K g})\end{array}$ \\
\hline 900 & 0.7665 & 0.08 & 2.000 \\
\hline 1800 & 1.1531 & 0.08 & 2.000 \\
\hline
\end{tabular}

It can be observed from table 2 that the rationalization coefficient for the whole-body SAR and body head SAR is adequate as recommended by ICNIRP exposure limits for our frequencies for tropics between $900 \mathrm{MHz}$ and $1800 \mathrm{MHz}$. This forms a basis for our study of tolerance when considered for occupational and popular users of cell phones.

\section{Comparative Study}

The comparison model used in this study involved experimentally based specific absorption rates (SAR) taken by electromagnetic detector for a variety of phone devices placed at $0.001 \mathrm{~m}$ from the human ear. While calls are received, the open waves are in the form of transverse electromagnetic waves and are therefore directly incident on the hearing diaphragm. The relative power density depends on the signal impulse and its propagation displacement. Table 3 shows the comparative study for a range of mobile cellular phones. The plots shown in figure 1 illustrate the power density and Specific absorption rate relative differentials such that the equation of the variance relationship give increasing Power Density (PD) with increasing Specific Absorption Rate (SAR). This however make us to conclude that while the SARs are recommended on increasing for standardization, the path location of the Base transmitting station are considered for power density reasons.

\begin{tabular}{|c|c|c|}
\hline Phone Model & SAR (mW/ Kg) & Power Density $\left(\boldsymbol{\mu} \boldsymbol{W} / \mathbf{~ m}^{2}\right)$ \\
\hline Nokia 3310 & 1.100 & 0.300 \\
\hline Nokia 3330 & 1.100 & 0.300 \\
\hline Motorola L7 & 1.500 & 0.400 \\
Motorola L9 & 1.500 & 0.400 \\
\hline Sagem C17 & 1.500 & 0.400 \\
\hline
\end{tabular}

Table 3: SAR -Power Density Measured from MOBILE Phones with MTN SIM Card 


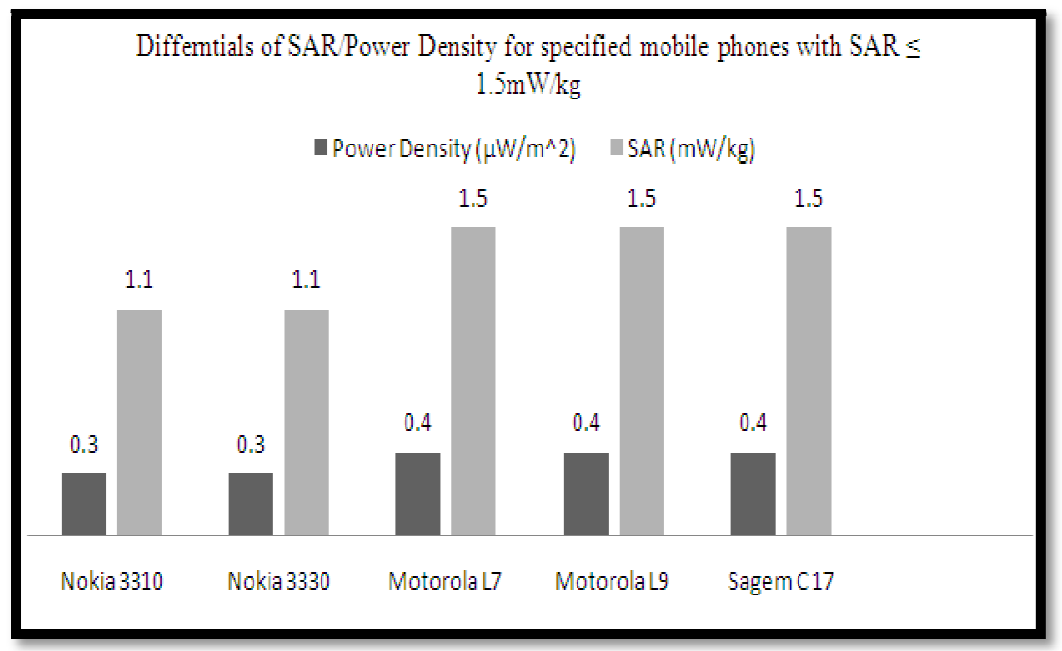

Figure 1

It is rarely observed that the $900 \mathrm{MHz}$ compared same mass density with $1800 \mathrm{MHz}$ but at conductivities of $0.7665 / 1.1531 \Omega^{-1} \mathrm{~m}^{-1}$ for $900 / 1800 \mathrm{MHz}$ respectively. See table 4 and table 5 for less than unity characteristic to favour tolerance reference. These are in agreement with the International Commission on Non-Ionizing Radiation (ICNIRP) on recommendation radiation safety as shown in table 1 . The percentage variations for mobile phones specific absorption rates have been calculated in other to specify reasonable tolerances as shown in figure 1, while this allow our recommendation based on observation that the performance level of our GSM cellular phones can be increased such that the higher the SARs the safer, helping users' density. Figure 2, shows the comparative tolerances. However, there are characteristic less than tolerance reference as to increase the SARs, hereby safeguarding against open wave on the diaphragm for a long period. The broadband frequencies band associated with tropical Africa to be considered in the tolerance limit for SARs at lower limits of $<1.5 \mathrm{~mW} / \mathrm{kg}$ and the upper limits of $\geq 1.5 \mathrm{~mW} / \mathrm{kg}$, for the conductivity and mass density as shown in figure 3 and figure 4

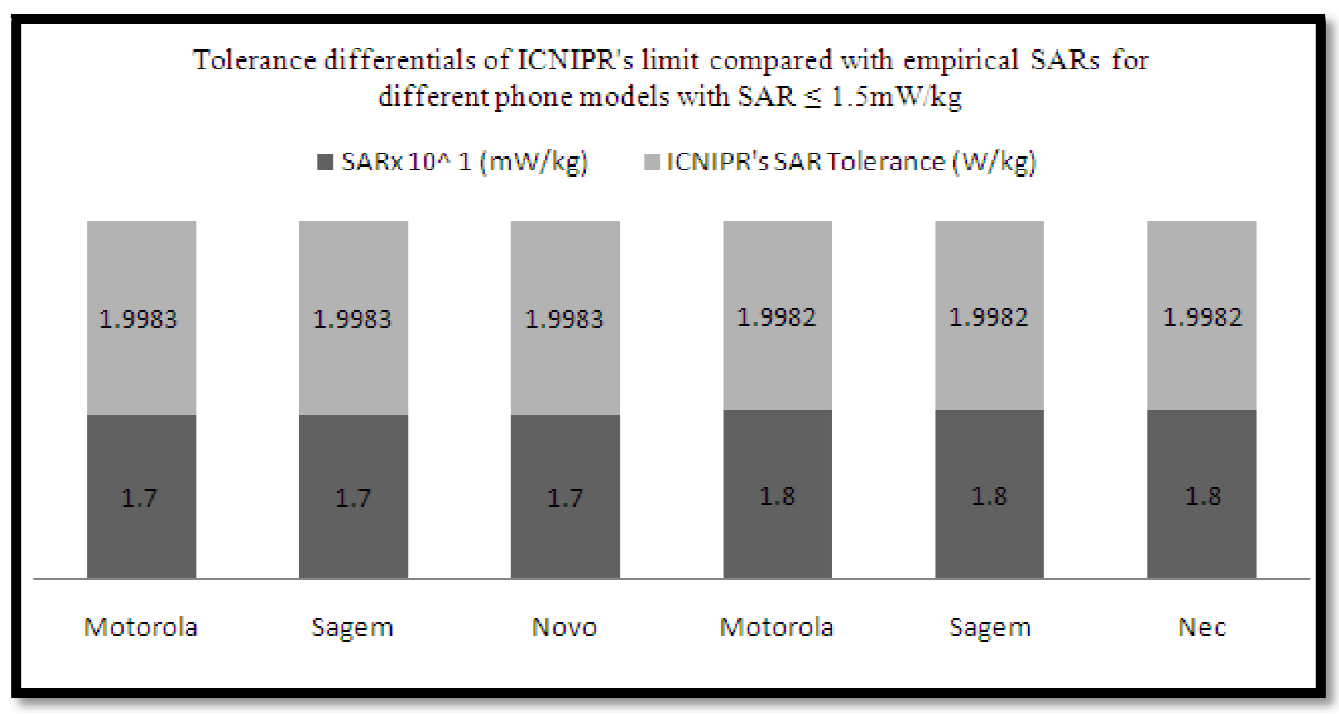

Figure 2

\begin{tabular}{|c|c|c|}
\hline Phone Model & SAR (W/ Kg) & Power Density $\left(\boldsymbol{\mu W} / \mathbf{~ m}^{\mathbf{2}}\right)$ \\
\hline Motorola L6 & 0.0018 & 0.500 \\
\hline Motorola L7 & 0.0017 & 0.400 \\
\hline Sagem MYX7 & 0.0018 & 0.500 \\
\hline Nec 616 & 0.0018 & 0.500 \\
\hline Novo & 0.0017 & 0.400 \\
\hline
\end{tabular}

Table 4: SAR -Power Density Measured from Mobile Phones with MTN SIM Card 


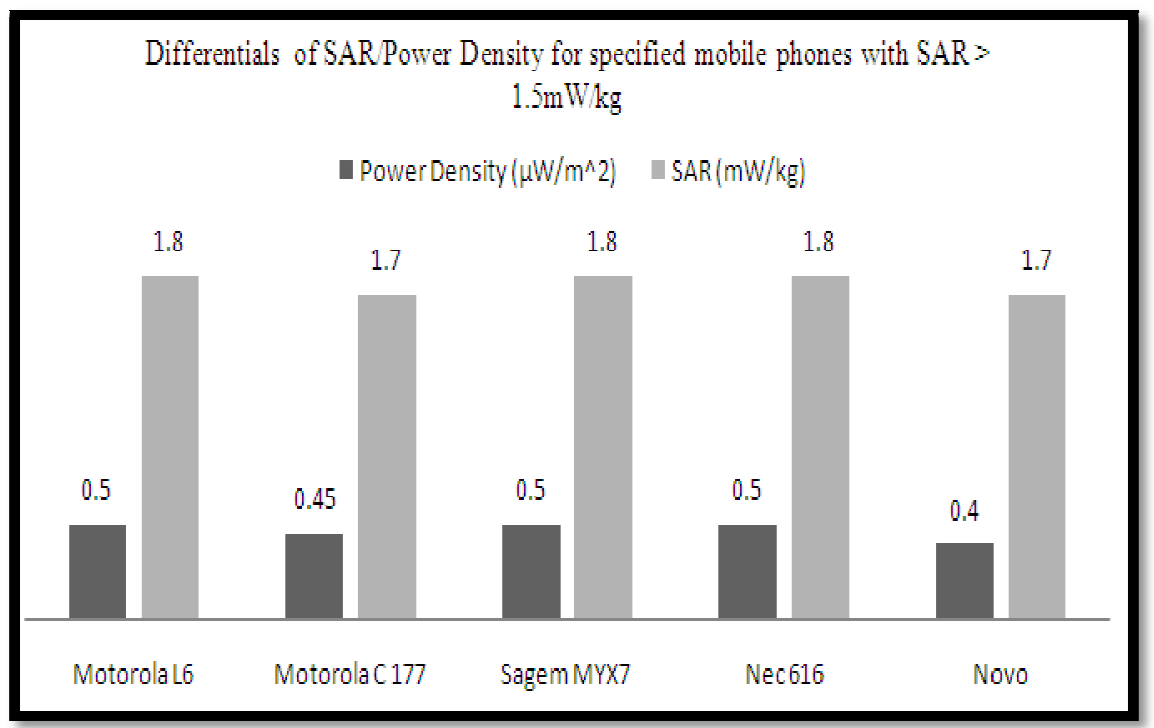

Figure 3: Graph Showing the Reference Comparisons of SAR and Power Density For Specified Mobile

\begin{tabular}{|c|c|c|c|}
\hline Mobile Phone Type & $\begin{array}{c}\text { Body Head SAR } \\
\text { (W/ Kg) }\end{array}$ & $\begin{array}{c}\text { Calculated Relative } \\
\text { ICNIRP's SAR tolerance } \\
\text { (W/ Kg) }\end{array}$ & $\begin{array}{c}\text { Tolerance advantage } \\
\text { percentage (\%) Inference }\end{array}$ \\
\hline Motorola & 0.0017 & 1.9983 & $<1$ \\
\hline Sagem & 0.0017 & 1.9983 & $<1$ \\
\hline Novo & 0.0017 & 1.9983 & $<1$ \\
\hline Motorola & 0.0018 & 1.9982 & $<1$ \\
\hline Sagem & 0.0018 & 1.9982 & $<1$ \\
\hline Nec & 0.0018 & 1.9982 & $<1$ \\
\hline
\end{tabular}

Table 5: ICNIRP's Relative Tolerance Limit Calculated For Sars $>1.5 \mathrm{~mW} / \mathrm{kg}$

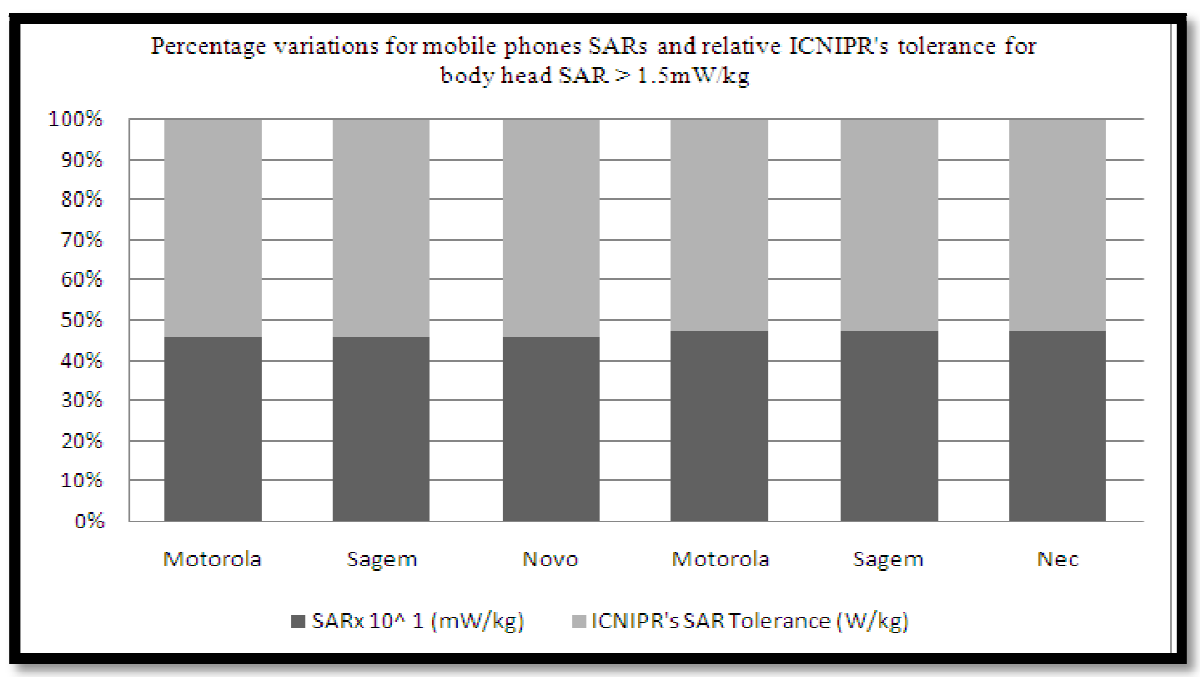

Figure 4: Variations for Mobile Phones Sars With ICNIPR's Tolerance for Body Head Specific Absorbtion Rates( Sars)

\section{Observations}

It is however recommended that precision for design of cell phones be considerably higher than $1.5 \mathrm{~mW} / \mathrm{Kg}$ specific absorption rate (SAR) in order to check luxury addictive attitude of the use of mobile cellulose in the tropics. Health endpoints or hazard associated with exposure to electromagnetic radiations be labeled Yellow on sheath of mobile devices. Set temperate- tropical criteria for the usage of GSM machines by also considering environmental and climatic factors as part of factor for future designs. Make potable probes likable to check the level of SARs by the occupational population (especially in the radiation industry) and the general public. The methodology used in the design of mobile devices should include environmental as well as climatic factors as to cater for radiation exposure conditions which may rarely result in changes in cognitive, learning and memory performance caused by RF-EMF exposure. Nonetheless, we recommend that our agencies and commission take our inferences into consideration so as to maintain a balance in cognitive performance of the human brain after (long dose) exposure to a pulsed electromagnetic field and thus continue to sustain a radiation harmless environment and a balance for a healthy population. 


\section{Conclusion}

The interest of human advantages derived from different phones will continue to be emphasized. That starts up our study for the different performance SAR levels with relative power densities as observed in this study. However, our plot grams have information for the awareness of public and occupational users of mobile phones. Nevertheless, our recommendation to radiation agencies include temperate-tropical differential of power failure in digital line signal of radiofrequencies propagation paths that quantifies that our most less than unity characteristics.

\section{References}

i. Cellhire, (2013) International Cell Phones. Retrieved 3

ii. Eliyahu et al (2006). Effects of radiofrequency radiation emitted by cellular telephones on the cognitive functions of humans bioelectromagnetics 27 (2): 119-126.

iii. Hartel, Levine and Livingstone (1999) Global System Mobile (GSM) Super phones, McGraw-Hill

iv. John Wargo et at (2012). Cell phones technology, exposures and health effects, Yale University, Environment and human health, inc.

v. Kuboye B. M.1, , Alese B. K.1, Fajuyigbe O.1, Adewale O. S. (2011) Development of Models for Managing Network Congestion on Global System for Mobile Communication (GSM) in Nigeria Journal of Wireless Networking and Communications vol1(1):pp 8-15

vi. Mehrotra, A. (1997) GSM System Engineering Artech home, Inc.1997

vii. Molisch, Andreas (2010). Wireless communication (second edition.). Oxford: Wiley-Blackwell. p. 591. 